\title{
Carbon Nanomaterials from Carbon Monoxide Using Nickel and Cobalt Catalysts
}

\author{
B. Liszka ${ }^{a, *}$, A. KRZToN ${ }^{a}$ AND M. PAWLYTA ${ }^{b}$ \\ ${ }^{a}$ Centre of Polymer and Carbon Materials, Polish Academy of Sciences \\ M. Curie-Skłodowskiej 34, 41-819 Zabrze, Poland \\ ${ }^{b}$ Institute of Engineering Materials and Biomaterials, Silesian University of Technology \\ Konarskiego 18A, 44-100 Gliwice, Poland
}

\begin{abstract}
Two catalysts, nickel and cobalt, supported on $\mathrm{MgO}$ were used for carbon nanomaterials deposition by $\mathrm{CO}$ disproportionation. The syntheses were performed at 795 and $900 \mathrm{~K}$ in the hydrogen atmosphere. The resulting products were investigated using atomic force microscopy, scanning electron microscopy, and high-resolution transmission electron microscopy. Although in the literature carbon nanofibres are expected to form in the hydrogen presence, we obtained carbon nanotubes, which were multiwall and twisted with the outer diameter of 10-120 $\mathrm{nm}$ and the tube length up to $10 \mu \mathrm{m}$.
\end{abstract}

PACS numbers: 81.07.-b

\section{Introduction}

Carbon nanotubes (CNTs) and carbon nanofibers (CNFs) are nowadays one of the most extensively studied materials. Carbon nanomaterials have attracted much attention because of their unique and advanced chemical, physical, magnetic and mechanical properties, which make them promising candidates for producing nanometer-sized electronic devices, nanocomposites, drug-delivery systems or chemical sensors [1-9].

Up till now several methods for synthesizing carbon nanomaterials have been used such as carbon arc discharge [10], laser ablation of graphite [11], and chemical vapor deposition (CVD) [12-14]. The last method enables the production of carbon nanomaterials at a comparatively low cost and large scale using catalytic reactions such as decomposition of hydrocarbons and disproportionation of carbon monoxide $[12,13]$. Many parameters influence the CNTs and CNFs growth in the CVD method. The most important factors determining the structure and yield of carbon nanomaterials are the temperature, pressure, flow and concentration of the reaction gas and the ratio of hydrogen to hydrocarbons or $\mathrm{CO}$ $[12,13,15]$.

The catalytic disproportionation of $\mathrm{CO}$ in the presence of $\mathrm{H}_{2}$ resulted in the deposition of carbon on the surface of the catalyst metal particles in a lamellar form while nanotubes were formed in the hydrogen free atmosphere [13]. In that process iron-family transition metals were frequently used as catalysts $[12,13,16-18]$. Supported $\mathrm{Ni}$ catalysts showed very high activity and the longest life for the decomposition of molecules containing

* corresponding author; e-mail: barbara.liszka@cmpw-pan.edu.pl carbon atoms at temperatures $773-873 \mathrm{~K}[12,19]$. Carbon monoxide disproportionation over supported cobalt catalyst led to the formation of carbon nanotubes at the temperatures in the range 633-973 K [13, 20].

So far the role of the catalyst in the growth of carbon nanotubes and nanofilaments has not been explained in detail. It seems that molecules containing carbon atoms such as hydrocarbons or CO are adsorbed and decomposed on the catalyst surface where the incorporation of carbon atoms into the metal particle takes place and metal carbide may form. Then the carbon atoms precipitate on the opposite surface of the catalyst particle and incorporate into graphene layers. Jablonski et al. [16] implied that the presence of hydrogen was a necessary factor in determining the morphology of the formed carbon. They suggested that in the hydrogen atmosphere, the active sites responsible for the decomposition of the carbon-gas interface were kept "clean" by $\mathrm{H}_{2}$. They also claimed that the higher the relative amount of hydrogen, the smaller amount of amorphous carbon were observed $[16,21]$.

The aims of our study is to prepare and investigate carbon nanomaterials in $\mathrm{CO}$ disproportional reaction, in the hydrogen atmosphere, using Ni and Co catalysts supported on $\mathrm{MgO}$.

\section{Experimental}

\subsection{The synthesis of nickel and cobalt catalysts}

The catalysts were prepared according to the method reported by Chen et al. [12]. The obtained solid residue was calcinated at $989 \mathrm{~K}$ in air for $5 \mathrm{~h}$ followed by the reduction in hydrogen presence at $900 \mathrm{~K}$ for $2 \mathrm{~h}$.

$\mathrm{Co} / \mathrm{MgO}$ catalyst was prepared using the same method except the substitution of the nickel nitrate hexahydrate 
for cobalt(II) nitrate hexahydrate $(\mathrm{POCH})$. The obtained cobalt catalyst was calcined at $989 \mathrm{~K}$ in air for $2 \mathrm{~h}$ and reduced in hydrogen atmosphere for $2 \mathrm{~h}$ at $1000 \mathrm{~K}$ [13].

\subsection{The synthesis of carbon nanotubes}

In this study carbon nanomaterial was prepared by the CVD technique. A quartz boat with the cobalt or nickel catalysts (40 mg) was placed into a quartz horizontal tube furnace (inner diameter $20 \mathrm{~mm}$ and length $620 \mathrm{~mm}$ ) and then the sample was heated in a flow of argon from the room temperature to $900 \mathrm{~K}$ and kept for $15 \mathrm{~min}$ in hydrogen atmosphere (5\% in argon balance). Next the feed gas $\left(20 \% \mathrm{CO}\right.$ and $5 \% \mathrm{H}_{2}$ in ratio $\left.1: 1\right)$ was introduced with the flow rate of $45 \mathrm{ml} / \mathrm{min}$.

The process was carried out for $2 \mathrm{~h}$. Finally the reactor was cooled down with argon to the room temperature.

Carbon nanomaterial were produced in analogous conditions at $795 \mathrm{~K}$.

\subsection{Characterization of catalysts and carbon nanomaterials}

The surface area and the average pore volume of the nickel and cobalt catalysts were measured by nitrogen physisorption at $77 \mathrm{~K}$ (Sorptomatic 1800, Carlo Erba). The surface areas were calculated from the linear form of the Brunauer-Emmett-Teller equation $\left(S_{\mathrm{BET}}\right)$. The average pore volume was determined by the BarrettJoyner-Harenda (BJH) procedure.

The true density was determined using a helium gas displacement pycnometer (Micromatrics 1305). The catalysts were also examined by X-ray diffraction (Philips PW 1140).

The carbon nanomaterials were observed by the scanning electron microscopy (FEG SEM Zeiss Supra 35, equipped with lateral and inlens SE detectors, and with an energy dispersive X-ray (EDX) analyzer), the high resolution transmission microscopy (HRTEM, TECNAI $\mathrm{G}^{2}$ equipped with an EDX analyzer) and the atomic force microscopy, AFM (MultiMode, di-Veeco, USA, CA with standard $125 \mu \mathrm{m}$ single-crystal silicon cantilevers).

\section{Results and discussion}

\subsection{Characterization of cobalt and nickel catalysts}

Figure 1 shows X-ray diffraction pattern of $\mathrm{Ni} / \mathrm{MgO}$ catalyst reduced in hydrogen atmosphere at $900 \mathrm{~K}$. One can observe peaks of $\mathrm{MgO}$ (cobalt radiation): $2 \theta=43.28$ $(d=2.43) ; 50.42(d=2.10) ; 74.10(d=1.48) ; 90.00$ $(d=1.27) ; 95.16(d=1.21)$ and $117.04(d=1.05)$. The last four are slightly shifted to higher angles, which can result from the presence of $\mathrm{NiO}$. $\mathrm{Ni}$ and $\mathrm{Mg}$ cations possess similar ionic radii $\left(0.070 \mathrm{~nm}\right.$ for $\mathrm{Ni}^{2+}$ and $0.065 \mathrm{~nm}$ for $\mathrm{Mg}^{2+}$ ) [12]. $\mathrm{NiO}$ and $\mathrm{MgO}$ possess cubic oxide structure (NaCl-type). The same dimensions of crystal structure result in an ideal solid solution $\mathrm{Ni}_{x} \mathrm{Mg}_{1-x} \mathrm{O}[12,22]$. Small peaks due to Ni: $2 \theta=51.92(d=2.04) ; 60.98$ $(d=1.76) ; 91.58(d=1.25) ; 114.91(d=1.06)$ indicate low reduction of $\mathrm{NiO}$ to $\mathrm{Ni}$ metal.

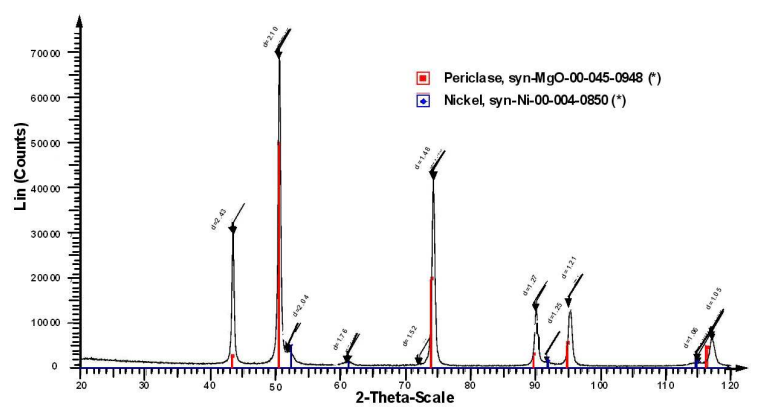

Fig. 1. XRD patterns of $\mathrm{Ni} / \mathrm{MgO}$ catalyst after hydrogen reduction.

The analogous situation is observed for $\mathrm{Co} / \mathrm{MgO}$ catalyst (Fig. 2). The peaks due to $\mathrm{MgO}$ are very close to the peaks of $\mathrm{CoO}$. The presence of solid solution $\mathrm{CoO} / \mathrm{MgO}$ causes small intensities of peaks assigned to Co metal (difficult in reduction $\mathrm{CoO}$ to $\mathrm{Co}$ ).

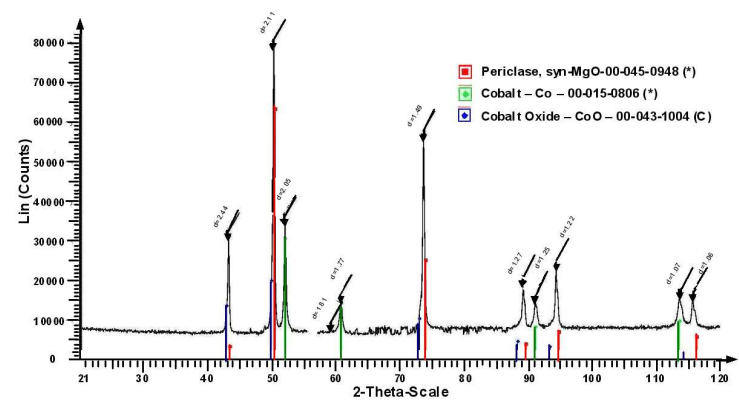

Fig. 2. XRD patterns of $\mathrm{Co} / \mathrm{MgO}$ catalyst after hydrogen reduction.

We have determined some characteristic parameters for our catalysts. The true density of $\mathrm{Ni} / \mathrm{MgO}$ is $4.76 \mathrm{~g} / \mathrm{cm}^{3}$ and $4.34 \mathrm{~g} / \mathrm{cm}^{3}$ for $\mathrm{Co} / \mathrm{MgO}$. The value of specific surface area is $29 \mathrm{~m}^{2} / g$ (Co catalyst) and $37 \mathrm{~m}^{2} / \mathrm{g}$ (Ni catalyst). The average pore volume measurements provide the values $0.10 \mathrm{~cm}^{3} / \mathrm{g}$ for the former catalyst and $0.14 \mathrm{~cm}^{3} / \mathrm{g}$ for the latter one.

\subsection{Characterization of carbon nanomaterial}

The results of carbon nanotube synthesis were proved by SEM, AFM, transmission electron microscopy and high resolution transmission electron microscopy (TEM and HRTEM) micrographs.

Figures 3a, b present AFM micrographs of the carbon nanomaterials obtained from $\mathrm{Ni} / \mathrm{MgO}$ catalyst in $\mathrm{CO}$ disproportionation at $900 \mathrm{~K}$. The nanofilament diameters are mostly from 10 to $120 \mathrm{~nm}$ and their length was up to $10 \mu \mathrm{m}$.

The typical SEM micrographs of the carbon nanomaterials obtained from cobalt catalyst (Fig. 4a,b for $795 \mathrm{~K}$ ) and nickel catalyst (Fig. 4c,d for $795 \mathrm{~K}$ ) are shown. Performed SEM observations have proved that the carbon nanomaterial is formed as a network with different 


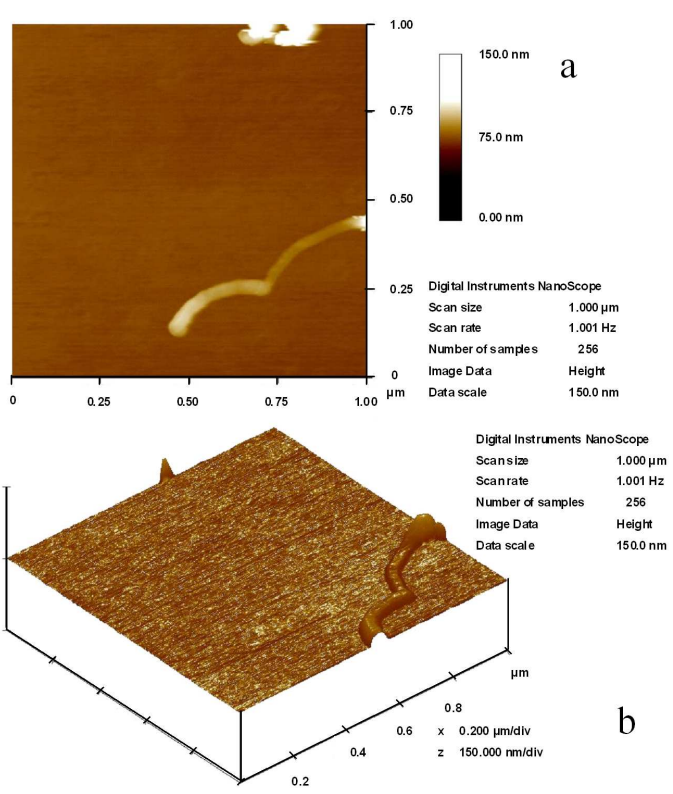

Fig. 3. Atomic force microscopy micrographs of nanomaterial formed at $900 \mathrm{~K}$ from $\mathrm{Ni} / \mathrm{MgO}$ (a) in $2 \mathrm{D}$ and (b) $3 \mathrm{D}$.

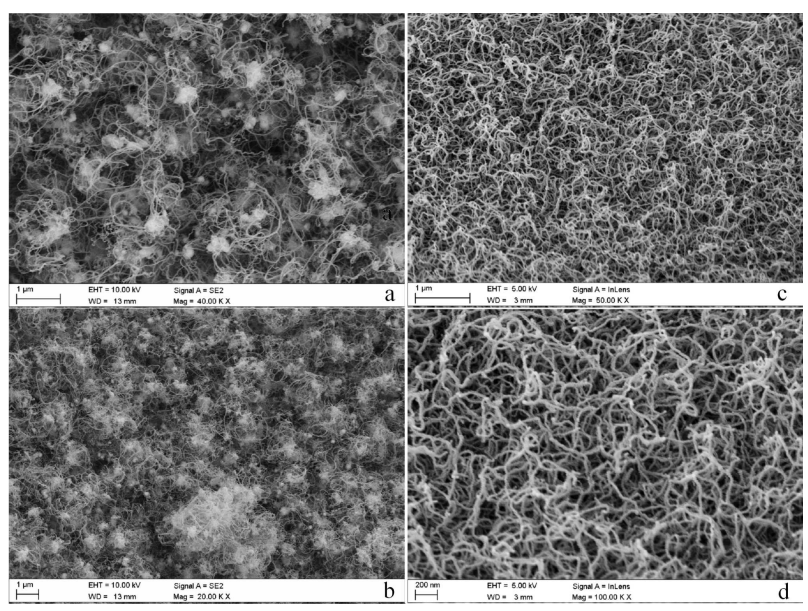

Fig. 4. SEM images of carbon nanotubes as obtained in $\mathrm{CO}$ disproportional reaction, in hydrogen atmosphere at $795 \mathrm{~K}$ from $\mathrm{Co} / \mathrm{MgO}(\mathrm{a}, \mathrm{b})$ and $\mathrm{Ni} / \mathrm{MgO}(\mathrm{c}, \mathrm{d})$.

package densities. The catalysts are visible as spherical shapes. The carbon nanomaterials obtained from the nickel catalyst are more homogeneous than the ones obtained from the cobalt catalyst, which contains large amount of remaining impurities. No significant differences are observed for the sample structures obtained for $795 \mathrm{~K}$ and for $900 \mathrm{~K}$.

Figure 5 shows the TEM image of the carbon nanomaterial obtained from nickel catalyst $(900 \mathrm{~K})$ as carbon nanofilaments. The dark object in the micrograph is the metal particle $(\mathrm{Ni})$. HRTEM of carbon nanomaterial from $\mathrm{Co} / \mathrm{MgO}(900 \mathrm{~K})$ is shown in Fig. 6a,b. These

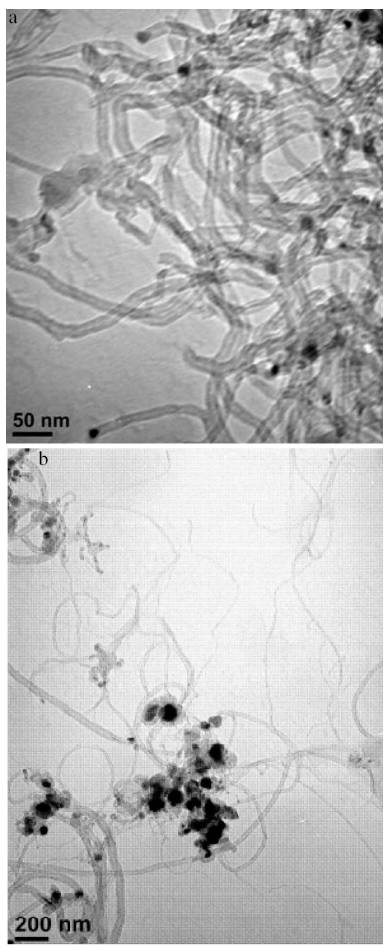

Fig. 5. Transmission electron microscopy of carbon nanotubes obtained at $900 \mathrm{~K}$ from $\mathrm{Ni} / \mathrm{MgO}$ (a) and $\mathrm{Co} / \mathrm{MgO}(\mathrm{b})$.

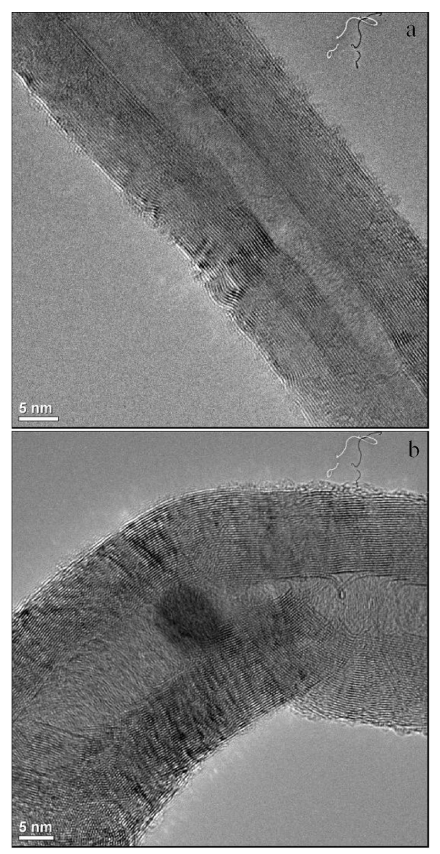

Fig. 6. High resolution transmission electron microscopy of carbon nanotubes obtained at $900 \mathrm{~K}$ from $\mathrm{Co} / \mathrm{MgO}$. Pure nanotube (a) and nanotube with $\mathrm{Co}$ nanoparticle (b). 
nanofilaments are inside empty like nanotubes. The dark object in the interior of the nanotubes is cobalt (Fig. 6b).

The number of graphene layers of nanotubes amounts to approximately 20 (Fig. 6a,b). The presence of hydrogen in this synthesis (ratio $\mathrm{CO}: \mathrm{H}_{2}=20 \%: 5 \%$ ) does not result in obtaining carbon nanofibers as expected but mostly carbon nanotubes. Indeed, it is not evident in Fig. 4a-d, if nanofiber or nanotubes are formed. Only just TEM and particularly HRTEM observation can clarify this question. However, the hypothesis about mere formation of carbon nanofibers in hydrogen atmosphere was settled with HRTEM studies, special inclination of the carbon layers with respect of the axis of the tube was the reason why nanomaterials produced were called nanofibers rather than nanotubes [13].

The carbon nanotubes formed by catalytical disproportionation of $\mathrm{CO}$ can possess many defects such as localized kinks (Fig. 5) or bends (Fig. 6b).

\section{Conclusions}

Carbon nanotubes have been successfully synthesized via carbon monoxide disproportionation using $\mathrm{Ni} / \mathrm{MgO}$ and $\mathrm{Co} / \mathrm{MgO}$ catalysts. The presence of hydrogen in this synthesis (ratio CO: $\mathrm{H}_{2}=20 \%: 5 \%$ ) does not result in our studies for obtaining carbon nanofibers but mostly carbon nanotubes. HRTEM studies show that in this method both catalysts allow to form carbon nanotubes and yield good results.

\section{Acknowledgments}

The authors are grateful to the Ministry of Science and Higher Education for the financial support (project No. PBZ-MEN-2/2/2006).

\section{References}

[1] S. Iijima, Nature 354, 56 (1991).

[2] R.H. Woodman, B.R. Klotz, R.J. Dowding, Ceram. Int. 31, 765 (2005).
[3] A. Leela Mohana Reddy, S. Ramaprabhu, Nanoscale Res. Lett. 3, 76 (2008).

[4] S. Bandow, S. Asaka, X. Zhao, Y. Ando, Appl. Phys. A 67, 23 (1998).

[5] J. Bernholc, C. Brabec, M. Buongiorno Ardelli, A. Maiti, C. Roland, B.I. Yakobson, Appl. Phys. A 67, 39 (1998).

[6] J. Sun, L. Gao, J. Electroceram. 17, 91 (2006).

[7] A. Pantano, F. Cappello, Meccanica 43, 263 (2008).

[8] Z. Liu, S. Tabakman, K. Welsher, H. Dai, Nano Res. 2, 85 (2009).

[9] Y. Wang, Z. Iqbal, JOM 57, 27 (2005).

[10] Y. Makita, S. Suzuki, H. Kataura, Y. Achiba, Eur. Phys. J. D 34, 287 (2005).

[11] I.G. Assovskii, G.I. Kozlov, Dokl. Phys. Chem. 388, 13 (2003).

[12] P. Chen, H.B. Zhang, G.D. Lin, Q. Hong, K.R. Tsai, Carbon 35, 1495 (1997).

[13] J.P. Pinheiro, M.C. Schouler, P. Gadelle, Carbon 41, 2949 (2003).

[14] J.F. Colomer, C. Stephan, S. Lefrant, G. Van Tendello, I. Willems, Z. Kónya, A. Fonseca, Ch. Laurent, J.B. Nagy, Chem. Phys. Lett. 317, 83 (2000).

[15] C. Vallés, M. Pérez-Mendoza, W.K. Maser, M.T. Martínez, L. Alvarez, J.L. Sauvajol, A.M. Benito, Carbon 47, 998 (2009).

[16] G.A. Jablonski, F.W. Geurts, A. Sacco, Jr., Carbon 30, 87 (1992).

[17] S. Inoue, T. Nakajima, Y. Kikuchi, Chem. Phys. Lett. 406, 184 (2005).

[18] X.Q. Wang, L. Li, N.J. Chu, Y.P. Liu, H.X. Jin, H.L. Ge, Mater. Res. Bull. 44, 422 (2009).

[19] S. Takenaka, S. Kobayashi, H. Ogihara, K. Otsuka, J. Catal. 217, 79 (2003).

[20] A.A. Khassin, T.M. Yurieva, V.I. Zaikovskii, V.N. Parmon, React. Kinet. Catal. Lett. 64, 63 (1998).

[21] J.W. Snoeck, G.F. Froment, M. Fowles, J. Catal. 169, 240 (1997).

[22] C. Song, W. Pan, Catalysis Today 98, 463 (2004). 